\title{
Child-Timing Desires in a Low Fertility Context:
}

\section{A Cohort Analysis}

\author{
Olusegun Sunday Ewemooje ${ }^{1}$, Acheampong Yaw Amoateng ${ }^{2}$, Elizabeth Biney ${ }^{3}$ \\ ${ }^{1}$ Department of Statistics, Federal University of Technology Akure, Nigeria \\ ${ }^{2,3}$ Population and Health Research Entity, Faculty of Humanities, North-West University (Mafikeng Campus), \\ South Africa
}

\begin{abstract}
Globally, there have been significant changes in human reproductive behaviour that have had profound effects on population growth. The outstanding feature of this demographic transition is that it unevenly distributed as its tempo has differed across the globe. Regardless of the magnitude or speed of the decline, two main reasons have been associated with low fertility, namely, changes in the average number of children born to a woman throughout her reproductive period and the timing of this event in the life course. This was the context of the present study as it sought to understand the recent fertility transition in South Africa by understanding the factors that shape the child-timing desires of women who are married or cohabiting. Specifically, the study sought to examine and compare the effects of selected sociodemographic factors on the desired child-timing of two cohorts of reproductive-aged women in South Africa, 15-34 years (younger women) and 35-49 years (older women). The results showed that increased parity, contraceptive use and increased household size significantly predicted desired child-timing for both groups of women. The study also found that belonging to a 'middle' wealth index category, higher education and living in certain parts of the country significantly predicted child-timing desires for younger women but not older women. Implications for policy interventions were discussed.
\end{abstract}

Keywords: Age cohort, Child-timing, Fertility desire, South Africa, Women 


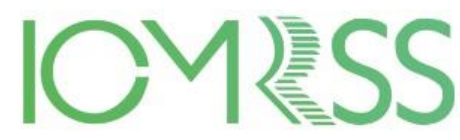

06-08 November, 2020 MUNICH, GERMANY

\section{Introduction}

Following the recent demographic transition around the globe, women are increasingly having fewer children (UN DESA/Population Division, 2017a). The global total fertility rate has decreased to below 2.5 children per woman, according to 2017 UN data (Roser, 2020; UN DESA/Population Division, 2017b). This is half the rate of what it was in the 1950s. However, the decline of the fertility rate is unevenly distributed as there are stark differences across and within regions of the globe. Regionally, sub-Saharan Africa's current average fertility rate of 4.93 children per woman lags behind that of Europe (1.62 children), North America (1.84 children), Latin America and the Caribbean (2.09 children), and even Asia (2.17 children) (UN DESA/Population Division, 2017b).

Even within regions, the speed of the decline of fertility rates has not been uniform either. For instance, within the high fertility region of sub-Saharan Africa, South Africa's fertility rate has substantially declined from 6 children per woman in 1950 to a low of 2.6 children in 2016, comparable with the global average, in a region of relatively high fertility (NDoH, Stats SA, SAMRC \& ICF, 2019; UN DESA/Population Division, 2017b).

While many explanations have been proffered for this demographic transition, changing trends of women's reproductive motivations cannot be ruled out. In other words, the declining fertility rates do not only suggest that women are choosing to have fewer children, but it also speaks to the timing of when they start the family building processes which includes childbirth and spacing of subsequent birth. In South Africa for instance, available data show that women's median age at first birth has risen slightly from 20.8 years in 1998 to 21.3 years in 2016 (NDoH et al., 2019). Additionally, women's median birth interval in South Africa has increased from 47.1 months in 1998 to 55.3 months in 2016 (NDoH et al., 2019). We posit in the present study that these changes in the patterns of family formation in South Africa are not random acts by couples and women as rational actors. We instead contend that the sources of these changing trends must lie in the everyday lived experiences of couples and individual women. In other words, the possible explanations of these demographic transitions range from changes in actors' social-cultural contexts and psychological dispositions.

Specifically, no matter the age or time women "decide" to begin childbearing, one cannot ignore the fact that motivation drives fertility behaviour. For instance, the decision about 


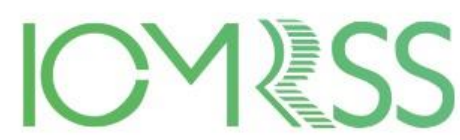

06-08 November, 2020 MUNICH, GERMANY

when to have children - the timing of childbearing - can be a voluntary individual choice; personal decisions women make freely with their partners (Bellieni, 2016). It can also be influenced by external conditions or pressures out of women's control, including societal norms, biology (miscarriages, sterility, infertility, subfertility), career, education etc. (Bellieni, 2016; The ESHRE Capri Workshop Group, 2001). Consciously or unconsciously, motivational forces invariably drive future fertility-related behaviours.

Accordingly, understanding child-timing - defined as the intention of having the first or subsequent child within a given period - can prove useful for future population projections and planning since the timing of childbearing has been implicated in current low fertility trends in Europe and other parts of the world (Batyra, 2016; Sobotka, 2004). Countries wishing to mimic similar demographic transition will benefit from understanding women's child-timing aspirations to design a more nuanced fertility-related policy as well as assess the extent of unmet family planning needs. Despite the predictive value of child-timing aspirations, it is a much less-explored dimension of fertility aspirations in sub-Saharan Africa. The empirical literature on child-timing desires and intentions in the region is scanty at best, especially, in South Africa. Even with the available limited empirical studies, the focus has often been on women or couples living with HIV/AIDS (see e.g. Bai et al. 2017; Marlow et al. 2012; Peltzer et al. 2018).

It was against this backdrop of the paucity of child-timing literature in sub-Saharan Africa that this study sought to understand what aspects of women's individual and social characteristics were associated with the desired timing of the first birth or conception of a (further) child. Specifically, the present study aimed to describe and compare the childbirthtiming desires of two age cohorts of in-union women using the 2016 South African Demographic and Health Survey data. 


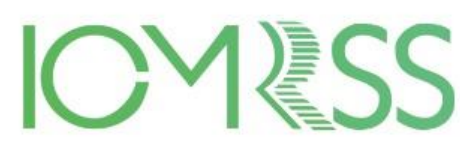

06-08 November, 2020 MUNICH, GERMANY

\section{Review of The Empirical Literature}

Generally, reviewing the research literature on women's childbearing aspirations (desires and intentions) is challenging because of the many different ways aspirations are conceptualised and measured in the literature (Casterline \& Agyei-Mensah, 2017; Philipov, 2011). The empirical literature on child-timing aspirations suffers from similar conceptual issues concerning how it is treated in the literature. The primary issue is how the concepts desires and intentions are frequently and erroneously conflated or used interchangeably, although the two terms are distinct. Miller (2011:78) clarifies the differences between the two terms wherein he posits that desire "is merely a wish to achieve an actionable goal", whereas intention goes beyond wishing to include a related commitment and plan for implanting said goals. Thus, desires precede intentions, although both are powerful antecedents of fertility behaviour.

Miller (2011) further contends that the conflation of the two constructs in the literature could be, among others, a consequence of conceptual confusion owing to inadequate or poor construct definitions utilised in many survey datasets. This is highly plausible considering that most questionnaire items used in demographic and health surveys, like the one used in this study measuring childbearing aspirations, are limited to what individuals want to achieve. Thus, without additional variable items on associated commitment and plans, one is only measuring "desires" not "intentions".

However, the desire-intention conflation is not so critical because it is not entirely uncommon for desires to bypass intentions in the flow of fertility decision-making (Miller, 2011:86). This is because having a child in itself is not the outcome of a rational decision or action by couples (Ajzen \& Klobas 2013; Kuhnt and Trappe 2013). Reproductive motivations and subsequent decision- making and behaviours are rather complex and dynamic. Despite the conceptual and measurement problems associated with the construct, the literature is not entirely lacking in empirical studies interrogating child-timing. However, it is worth noting that because of the limited number of available papers the subsequent literature review includes studies on both child-timing desires and intentions.

It is a truism that most women want to have children (Matovu, Makumbi, Wanyenze \& Serwadda, 2017; Oyediran, 2005). This is especially the case in many sub-Saharan African cultures where a child or children are central to the definition of family following entry into a 


\section{3rd International Conference on Modern Research in}

SOCIAL SCIENCES

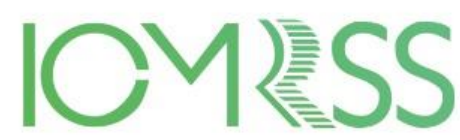

06-08 November, 2020 MUNICH, GERMANY

relationship (marriage or cohabitation) (Kuhnt \& Trappe, 2013; Spéder \& Kapitány, 2009). Moreover, in most African societies, a union provides the normative context within which most childbearing occurs (Agaba, Atuhaire \& Rutaremwa, 2010; Palamuleni, Kalule-Sabiti \& Makiwane, 2007). However, the desires and decisions about the timing into motherhood and/or spacing of births may differ from one woman to another in the life course during which as a result of their varied social, cultural and economic contexts, their desired child-timing is influenced by various micro and macro factors.

At the individual level, factors like age, ethnicity, parity and use of contraception have strong influence on women's reproductive aspirations and behaviour. Concerning age, biology may be a constraining factor for all women as fecundity naturally declines as women age (Benzies et al., 2006). Moreover, there is a marked decline in women's ability to conceive especially after the age of 35 . However, because of technological advancement, this biological constraint can be breached in an increasingly industrialised society like South Africa. Owing to the age-related fertility decline imposed by nature on women, it is expected that generally their childbearing desires (be it quantum, timing, sex preferences) will be formed and professed relatively early in life, whether or not acted on at the time (Heywood, Pitts, Patrick \& Mitchell, 2016). Nonetheless, there are observable age differentials in women's child-timing desires. In some cultural milieux, younger women are more likely to delay childbearing and/or extend birth intervals compared to older women (Abbas et al., 2013; Batyra, 2016; de Jonge et al., 2014). While in other contexts, the inverse has been observed (Haile et al., 2016; Hailu \& Gulte, 2016; McGuire \& Stephenson, 2015). The mixed findings in the literature suggest that the effect of age is not only linked to women's different life courses but other contextual factors.

Cultural norms and practices shape childbearing behaviour generally and in unique ways (Lailulo \& Susuman, 2018). For instance, most African cultures have pro-natalist attitudes and expectations as a high premium is placed on having children (Amoateng et al., 2007; Bimha \& Chadwick, 2016). In such contexts, women's motivation to have and when to have children will be strongly influenced by the prevailing cultural pressures. In the South African context, culture - measured as ethnicity, using home language spoken as a proxy would give a more nuanced understanding than racial variations often captured in national data. 


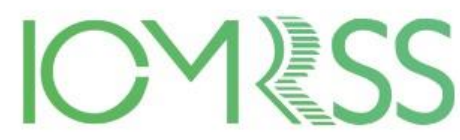

06-08 November, 2020 MUNICH, GERMANY

Parity, the number of children women have, influence the intensity of women's childtiming desires and in some cases, can act as a deterrent for childbearing. Accordingly, women who have more living children at a point in time (increased parity) have been found desiring to slow down childbearing and/or have protracted birth spacing (de Jonge et al., 2014; McGuire $\&$ Stephenson, 2015). Women who already have living children may have already achieved, or may be close to achieving, their desired family size and therefore be less motivated to get pregnant sooner or even ever (Yohannes et al., 2011). Childless women, on the other hand, are likely to have early child-timing desires, especially if they have been trying to conceive and/or experience multiple miscarriages. That is to say, the more children women have, the less likely they are to desire children altogether. However, it is still possible for women with higher parity to want children if a child-sex preference is an issue in their culture and has not been achieved.

The use of contraceptives in itself is a fertility-constraining behaviour (Cheng, 2011), therefore it can be seen as both a consequence and determinant of child-timing desires. Thus, women using contraception, compared to non-users, are a select group that have either decided to delay childbearing or decided that they do not want children. Accordingly, most studies have associated contraceptive use with deferred child-timing and/or protracted birth spacing (Hailu \& Gulte, 2016; Matovu et al., 2017; McGuire \& Stephenson, 2015; Yohannes et al., 2011).

Aside from individual characteristics, socioeconomic factors such as women's educational attainment, employment status and wealth index have strong implications for their desired child-timing, because of the direct and indirect costs associated with having and raising children (Wei, Xue \& Wang, 2018). That is, the decision of whether and when to have a child is a question of economics as couples consciously or unconsciously do a cost-benefit analysis as a result of the costs for childcare, schooling, and opportunity cost in time that is needed for pregnancy (Wei, Xue \& Wang, 2018). Additionally, both education and employment are characteristically competing domains with childbearing (Miller, 2011).

The economic argument is more salient when wealth index is considered. There are economic fears associated with having and raising children, real or perceived. Having greater financial security helps dissuade some of these fears. Consequently, a general discovery in empirical fertility literature is that wealth and childbearing are negatively correlated (Jones \& Tertilt, 2006; Manfredini \& Breschi, 2008). However, critical contextual comparisons will reveal that the relationship between socioeconomic status and fertility is more ambiguous and 


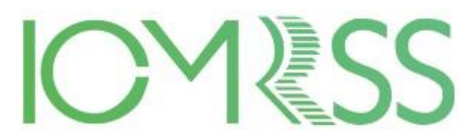

06-08 November, 2020 MUNICH, GERMANY

less clear than it seems. Nonetheless, some studies have found that women belonging to the middle and rich wealth index categories are more likely to have shortened child-timing compared to their poorer counterparts (Abbas et al., 2013; Yohannes et al., 2011), while others have observed the opposite effect (Abdel-Fattah et al., 2007; de Jonge et al., 2014; Khan et al., 2016; Hailu \& Gulte, 2016; McGuire \& Stephenson, 2015). The documented mixed effect of wealth index on women's child-timing is indicative of a complex relationship. For some women, the varied lifestyles that come with wealth might make them have protracted childbearing desires (Roser 2020), while for others, the presence or absence of wealth is not a deciding factor for planning a child (Ciritel et al., 2019).

Studies conducted in different cultural contexts have confirmed the fact that women's increased education and employment or career commonly have a delaying impact on their child-timing desires, intentions and transition to motherhood (Batyra, 2016; Benzies et al., 2006; Ferre, 2009) as well as birth spacing practices (Abbas et al., 2013; Haile et al., 2016; Khan et al., 2016; Lien \& Wang, 2016; Yohannes et al., 2011). However, the converse has also been found in other contexts where some women with higher education and/or working will want early childbearing or shortened birth spacing (de Jonge et al., 2014; McGuire \& Stephenson, 2015). Some scholars have argued that for these women, there may be a need to constrict their childbearing years to free up time to participate in other activities outside the home (de Jonge et al., 2014; Yohannes et al., 2011).

Other important factors that are likely to shape women's child-timing aspirations include residential geography (i.e. place and province) and living arrangements. Empirically, there are notable residential differences in both the timing and rate of childbearing of women (Abbas et al., 2013; Batyra, 2016; Khan et al., 2016; Rabbi, 2014; Yohannes et al., 2011). Conventionally, women in urban settings have delayed transition into motherhood and protracted birth spacing compared with rural residents as a result of such constraints as housing shortages and childcare costs in urban settings. This pattern is replicated in the South African context (NDoH et al., 2019; Palamuleni, Kalule-Sabiti \& Makiwane 2007). It can be expected that women's child-timing desires will mimic the observed residential differentials in women's fertility behaviour. In South Africa women's desired child-timing is expected to vary across provinces because of the variations in provincial socioeconomic development. Moreover, in South Africa, since women's living arrangements have been found to modify and mediate the 


\section{3rd International Conference on Modern Research in}

SOCIAL SCIENCES

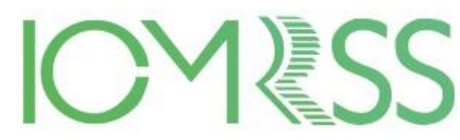

06-08 November, 2020

MUNICH, GERMANY

effects of other socio-economic factors on fertility (Moultrie \& Timaeus, 2001), household size (the number of household members) is expected to shape their child-timing desires.

The individual and socioeconomic factors discussed above are likely to affect different groups of women uniquely. For instance, women in different age cohorts are at different stages in the life course which will affect their childbearing desires (Aggarwal et al. 2001). Similarly, in-union women experience different pressures to single women, which will affect their fertility motivations. Therefore, this study compares the child-timing desires of in-union younger women (15-34 years) to those of older women (35-49 years) in examining the impact of selected socio-demographic factors across the two broad age cohorts. The two age groups are also informed by the fact that fecundity naturally declines as women age, especially after the age of 35 . Thus, the younger cohort is within the fertility prime whilst the older cohort is nearer the end of the reproductive range. Consistent with the study's design, we contend that the impacts of the socio-demographic factors will be different across the two age cohorts.

\section{Research Methodology}

\section{Sampling Procedure}

The data for the study come from the 2016 South Africa Demographic and Health Survey (SADHS). The survey was carried out using multistage cluster sampling design under the auspices of Statistics South Africa and the Medical Research Council between July and November 2016 to deliver reliable data on fertility levels, marriage, sexual behaviour, contraceptive use, maternal and child health, HIV/AIDS and other sexually transmitted infections, and other adult health issues that can be used by researchers and policymakers to appraise and improve present programs.

A nationally representative sample of 8,514 women aged 15-49 years in 11,083 selected households was successfully interviewed. Women who have never been married (i.e. single), those who were undecided or unsure of childbearing or timing, the sterilised or declared infecund and or those who have never had sex were excluded for the purposes of the present study. Thus, the analyses presented in this study is limited to 3,380 women of reproductive age who are in a union (i.e. currently married or living together with a partner as if married) 


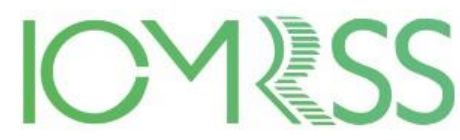

06-08 November, 2020 MUNICH, GERMANY

\section{Measures}

The outcome variable in this study is child-timing desire, measured by the question: "how long would you like to wait from now before the birth of a(nother) child?" The responses considered were trichotomized as "wants no more", "wants within 2 years" and "wants after 2 years". The study analysed the desired child-timing among the two age cohorts: young women "15-34 years" and older women "35-49 years" respectively.

The cultural, demographic and socioeconomic variables used as independent variables include ethnicity, level of education, employment status, wealth index category, parity, place and province of residence, contraceptive use and household size. All variables are categorised (see Table 1).

\section{Statistical analysis}

The analysis is restricted to married and cohabiting women of reproductive age grouped into two main age cohorts: younger (15-34 years) and older women (35-49 years). First, we use descriptive analysis to describe distributions of the background characteristics of the respondents. In stage two, a bivariate model using Chi-square is used to examine the relationships between desired child-timing and selected socio-demographic variables.

Stage three of the analysis comprises a series of multivariate investigations to identify predictors of child-timing desires. First, a multicollinearity diagnostic test is performed to test for any collinearity between the explanatory variables. Thereafter, a forward stepwise multinomial logistic regression technique is then used to identify the explanatory variables that best predict women's child-timing desires.

Multinomial regression analyses are then conducted progressively, taking into account the predictive power of the variables. Demographic and socio-economic variables are introduced in the analysis one after the other to assess the best predictors using forward stepwise model selection. All determinants whose association reached significance with a pvalue $<0.05$ are included in the final adjusted model. The results are interpreted using Odds Ratios (ORs), with variables deemed to significantly predict desires if the p-values associated with their ORs are less than 0.05. Analyses for this study are done using SPSS version 25. 


\section{Results}

\section{Background characteristics}

Table 1 presents the distributions of the background characteristics of the study population. The results show that more than half $(55.2 \%)$ of the respondents were older women (35-49 years) and $44.8 \%$ were younger women (15-34 years). More than one-third of the respondents belonged to the Nguni (38.7\%) and Sotho (34.3\%) ethnic groups; one-in-ten (10\%) were English; $8.9 \%$ were Afrikaans and $8.1 \%$ were Tshivenda/Xitsonga.

Seven-in-every-ten $(70.2 \%)$ of the respondents had secondary level education; $17.2 \%$ had below-secondary level education, and $12.6 \%$ had tertiary-level education. Just under half $(47.4 \%)$ of the respondents were employed and $52.6 \%$ were not employed. Regarding household wealth index, slightly less than two-fifths of the respondents were in the 'poorer' (39.3\%) and 'richer' $(37.7 \%)$ categories respectively; just over a fifth $(23 \%)$ were in the 'middle' wealth category. Older women constituted the majority in all wealth categories.

Slightly more than half $(52.4 \%)$ of the respondents were using some form of contraceptives. Most (43.6\%) of the respondents had three or more children; three-out-of-ten (30.8\%) the respondents had two children; $18.2 \%$ of them had only one child and $7.4 \%$ of ten had no children. Younger women were overrepresented in all parity groups, except among those with three or more children.

Over three-fifths $(61.2 \%)$ of the respondents resided in urban areas; older women constituted the majority in all geographic types. Most of the respondents lived in Mpumalanga (13.1\%), Gauteng (12.8\%) and Limpopo (12.4\%) provinces. Finally, over half (56.9\%) of the respondents lived in households consisting of 3-5 people; just under a quarter (23.6\%) lived in households of six or more persons; $19.5 \%$ lived in households of 1-2 people. 


\section{INSERT TABLE 1 ABOUT HERE}

\section{Prevalence and patterns of child-timing desires by background characteristics}

Overall, just under one-third (31.2\%) of the sampled women reported a desire for a(nother) child in a given period, while more than two-thirds (68.8\%) of the women reported the desire to limit childbearing completely. Of the women who reported childbearing plans, the majority $(68.8 \%)$ reported wanting a(nother) child sooner (within 2 years), rather than later (after 2 years) (31.2\%). Further, younger women more frequently reported wanting a(nother) child sooner $(59.5 \%)$ and later $(89 \%)$ than older women. Conversely, older women more frequently (64.8\%) reported intention not to have a child; thus, had desires to limit childbirth completely.

The results of the bivariate analyses using the Chi-square test in examining the associations between selected socio-demographic factors and desired child-timing showed a significant association with parity, household size and contraceptive use for all women, irrespective of age cohort (Table 2). Further, the desired child-timing were significantly associated with educational level, wealth index and province of residence for younger women only.

\section{INSERT TABLE 2 ABOUT HERE}

\section{Multinomial regression results}

The combined results for separate multivariate analyses for the two groups, younger women (15-34 years) and older women (35-49 years), using multinomial logistic regression techniques are presented in Table 3. The results show that the use of contraceptives, increased parity and increased household size significantly predict women's desired child-timing for both age cohorts. On the other hand, tertiary-level education, belonging to the 'middle' wealth category, and province of residence significantly predict child-timing desires for younger women only. 


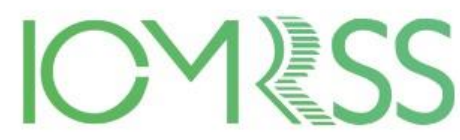

06-08 November, 2020 MUNICH, GERMANY

Specifically, the results show that women who use some form of contraceptive, irrespective of age group, are more likely to want to delay childbearing compared to non-users. Thus, contraceptive users are more likely to desire to delay childbearing by at least two years, with the odds higher for older women $(\mathrm{OR}=2.79, \mathrm{CI}=1.13-6.88)$ than younger women $(\mathrm{OR}$ $=1.46, \mathrm{CI}=1.02-2.10$ ). For parity, the odds of wanting a(nother) child either in the short or long term significantly decrease as parity increases; the relationship is stronger for both groups of women especially when they already have at least two children. Similarly, compared with those living in 1-2-person households, women living in six or more persons households are significantly less likely to want a child in the short-term (within two years) with a distinctly stronger finding for younger women $(\mathrm{OR}=0.31, \mathrm{CI}=0.18-0.53)$ than older women $(\mathrm{OR}=$ $0.51, \mathrm{CI}=0.30-0.85)$. Also, younger women living in 3-5-persons households are significantly less likely to want a child in the short-term $(\mathrm{OR}=0.65, \mathrm{CI}=0.43-0.99)$.

Aside from the predictors that are common for both groups of women, others emerged as unique to younger women only. The results indicate that young women's child-timing desires increase with their level of education. This positive effect of education on child-timing desires is particularly stronger for young women with tertiary-level education $(\mathrm{OR}=2.20$, CI $=1.03-4.72$ ). Also, the results show that young women belonging to the 'middle' wealth index category are significantly more likely to have shorter child-timing desires $(\mathrm{OR}=1.69, \mathrm{CI}=$ 1.13-2.53) compared to those in the 'poorer' wealth category. Finally, compared to those in Limpopo, young women living in the Free State, Kwa-Zulu-Natal, North West, Mpumalanga and Gauteng provinces are significantly less likely to want delayed child-timing. Moreover, younger women living in the Northern Cape are significantly less likely to have either early or delayed child-timing desires, indicating a general desire to limit childbearing all together.

INSERT TABLE 3 ABOUT HERE 


\section{3rd International Conference on Modern Research in}

SOCIAL SCIENCES

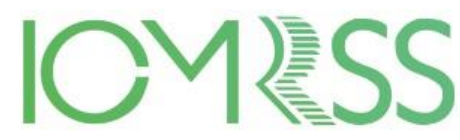

06-08 November, 2020

MUNICH, GERMANY

\section{Discussions}

In the past five decades, there has been a notable demographic transition as fertility levels have steadily declined in most parts of the world (Roser 2020). Aside from the actual quantum (i.e. the total number of children born over her reproductive period), birth timing and spacing has great bearings on the total fertility rate. Since fertility behaviours are preceded by motivations or aspirations, understanding child-timing and its associated factors are critical for more nuanced fertility-related population interventions targeting high fertility regions like subSaharan Africa. Present study aimed at assessing the role of selected demographic and socioeconomic variables that influence child-timing desires among in-union women of reproductive age in South Africa using the 2016 SADHS data. It compared the child-timing desires of two age cohorts, younger women (15-34years) and older women (35-49 years) to gain a nuanced understanding of the socio-demographic variations in women's fertility patterns.

The study found that on the whole more women of reproductive age in South Africa desire to limit childbearing completely. Among the women who had childbearing aspirations, younger women were overwhelmingly represented as nearly two-thirds of them reported wanting a(nother) child. This finding corroborates existing empirical findings in the literature that associate younger age with intentions to have children and older age with desires to limit childbearing (e.g. Bandehelahi et al. 2018; Matovu et al. 2017).

The observed differences in childbearing aspirations between the two cohorts of women simply reflect the different stages in these two cohorts of women's life courses in terms of reproductive plans. Thus, younger women could simply be at the early stages in the family formation process and are, therefore, more likely to have their active childbearing years ahead of them. Older women, on the other hand, may be closer to or may have already achieved their desired family size, and therefore, have no need or desire for additional children (de Jonge et al., 2014; McGuire \& Stephenson, 2015).

A closer look at the time dimension of childbearing desires shows that most of the women, irrespective of their ages, had shorter child-timing desires or desired to have children within 2 years rather than later. This is hardly surprising for two reasons. First, since fecundity naturally declines as women age, it is expected that childbearing aspirations will be expressed early on in life (Heywood et al. 2016). Secondly, the 20-35-year range is deemed the most 
viable period for childbearing as thereafter the ability to conceive markedly declines (Bellieni 2016). Therefore, women who intend or desire to have children would want to do so in the shortest possible time. This is particularly true for older women who are past the optimum fertility limit.

The study also found that the socio-demographic contexts within which women live affect their reproductive plans. In the South African context, some socio-demographic predictors apply to all groups of women, while others are age-specific. In the bivariate analyses, several associations confirmed some empirical expectations regarding the socio-demographic determinants of childbearing aspirations. Child-timing desire was generally associated with parity, household size and contraceptive use for all women, but associated with educational level, wealth index and the province of residence only for younger women. These findings were persisted after all other factors were taken into account in the multivariate analyses.

For instance, we found a positive relationship between contraceptive use and delayed child-timing desires in South Africa, a finding which corroborates previous studies from other contexts that have reported a link between contraceptive use and women's increased desire to postpone childbearing (Creanga, Gillespie, Karklins \& Tsui, 2011; Hailu \& Gulte, 2016; Yohannes et al., 2011). Since contraceptives are fertility-constraining methods (Cheng, 2011), the use of contraceptives can be seen as a consequence of a positive effort to delay childbearing, or in the case of older women, limiting childbirth altogether. The decision to use contraceptives could be individually devised or influenced by a partner. Nonetheless, women using contraceptives are a select group of individuals that desire to or have decided to delay childbearing and/or decided not to have (any) more children.

The present study also found that increased parity increased women's desire to limit childbearing as the odds of wanting children either in the short-term or later decreased once a woman already had two or more children. This finding corroborates previous studies in other contexts (de Jonge et al., 2014; McGuire \& Stephenson, 2015). It is understandable for the desire to get pregnant again to diminish or cease altogether as women reach their desired or ideal family size (Yohannes et al., 2011). It is also plausible that childcare constraints are a consideration at older ages given the inverse relationship between age and income.

Lastly, women who live in larger households of three or more people have shortened child-timing desires, suggesting a general desire to delay childbirth by at least two years. This 


\section{3rd International Conference on Modern Research in}

SOCIAL SCIENCES

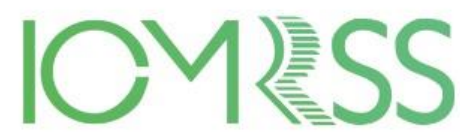

06-08 November, 2020

MUNICH, GERMANY

is particularly strong for younger women in South Africa, who in all probability may be residing with parents or parents-in-law. It is also possible that the overcrowding conditions common in larger household's act as a deterrent for some women and so be less inclined to add additional children, at least in the short-term.

Aside from the predictors that apply to all women, the study found that increased education, belonging to the 'middle' wealth index category and province of residence influenced child-timing desires for younger women. With regard to education, the study found that there was a linear relationship between education and desire to limit childbearing amongst the younger age cohort of women. Specifically, it was found that younger women in South Africa with tertiary-level education had strong desires to delay childbearing compared to those with less than secondary-level education. It is possible that the majority of these women are still in the process of completing their tertiary qualification and as such would want to postpone childbirth as the two are often competing activities. Perhaps the young women who have attained their tertiary qualifications may want to postpone childbearing to establish careers to garner returns for their investment in education; after all, they are still within the viable age for conceiving. Whatever the rationale, the finding supports the view that childbearing often competes with other life course activities such as the pursuit of education and participation in the labour force (Miller, 2011). In fact, in a study of undergraduates students at a public university in South Africa, Amoateng (2017) found that most of the youth who were born after the country's 1994 democratic transition were interested in pursuing education and careers unlike their parents whose education was largely truncated as a result of their active involvement in the 1970s' liberation politics in the country.

The present study also found that increased wealth reduced younger women's childtiming intentions, particularly belonging to the 'middle' wealth index category significantly shortens their child-timing desires. This is probably due to the fact that for affluent women, the economic fears associated with having and raising children that commonly influence reproductive plans of many, may not be there; they have higher financial security and liberty to both desire and plan for childbirth in the short-term. It is noteworthy that the pursuit of education and devotion to their careers by young South African women do not discourage them at all from entry into motherhood but they do so after they have accumulated enough wealth or resources to be able to afford it. 


\section{3rd International Conference on Modern Research in}

SOCIAL SCIENCES

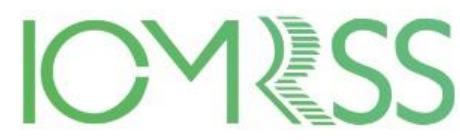

06-08 November, 2020

MUNICH, GERMANY

Finally, the study found that most women in South Africa, compared to those who live in the Limpopo province, are more likely to want no more children. The Limpopo Province is mostly rural and possibly the involvement of women in that province in mainly agrarian lifestyles which are mostly compatible with family life explains their pronatalist aspirations. So, the desire to limit childbearing by women who live in other provinces is probably reflecting the increasing urbanisation of the society which is gradually weakening cultural norms, beliefs and practices in the face of Western norms ones.

\section{Conclusion and Policy Implications}

African societies have been in transition ever since the continent came out of isolation from the rest of the globe through the colonial project and its corollaries of Westernisation and urbanisation. Through these coordinates, the social structures of African societies have been transforming largely in the direction of the western socieities that subjugated the continent. While almost every sub-Saharan African institution has or is undergoing change, the present study has focused attention onone fundamental institution: The Family.

The traditional African family was underwritten by such cultural norms and expectations as early and universal marriages and the the presence of a large number of children which essentially defined the family as a social institution. However, following the wholesale transformations of these traditional institutions, the institution of the family has followed suit as evidenced by changes such as declining fertility, non-marriage and increasing divorces as a result of the changes in other traditional social, economic and cultural institutions.

The present study has underscored the fact that the central family event of childbearing-fertility behaviour-is a function of these other socio-cultural institutions and as such as they have changed, they have engendered the changes we continue to witness in fertility behaviours of African actors through changes in individual Africans' psychological dispositions as desires, and intentions or aspirations.

Moreover, the present study has demonstrated that while in sub-Saharan Africa, modernisation through measures such as formal education, urbanisation and wage employment has been the main driver of social change, these social transformations in attitudes and behaviours are not always uniform or unidirectional in nature. In the case of child-timing 


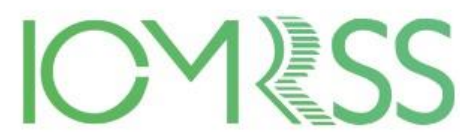

06-08 November, 2020 MUNICH, GERMANY

desires for instance, while factors such as wealth engender shortened child-timing, others, like education, discourage some women from having such motivations.

Concerning policy, the findings of the present study suggest that general anti-natalist policies in South Africa, rather than treating all women as a homogeneous group, should target educated and wealthy young women who intend having children as the present study has highlighted. Besides this targeted intervention, family planning educational campaigns and services should be strengthened and broadened as it is having traction in the population. Specifically, a concerted effort should target younger women through well-crafted family planning programmes and services, simultaneously ensuring the availability of contraceptives to all women.

\section{Study's Limitation}

Although this study makes use of a large nationally representative dataset, it is still a crosssectional design. Therefore, care must be taken when interpreting the findings. Notably, the analyses only provide evidence of a statistical relationship as opposed to a causal relationship.

\section{References}

Amoateng, A.Y. The End of Politics by the Youth? Higher Education, Youth Identity and Recession of Political Participation by South Africa's "Born-frees": The Case of Undergraduate Students at a Public University. International Journal of the African Renaissance Studies, 10(1): 102-119.

Abbas, N., Shaikh, I., \& Bari, I. (2013). Socioeconomic and demographic dynamics of birth interval in Pakistan. Pakistan Journal of Public Health, 3(2), 35-39.

Abdel-Fattah, M., Hifnawy, T., El Said, T. I., Moharam, M. M., \& Mahmoud, M. A. (2007). Determinants of birth spacing among Saudi women. Journal of Family \& Community Medicine, 14(3), 103-111.

Agaba, P., Atuhaire, L. K., \& Rutaremwa, G. (2010). Determinants of age at first marriage among women in western Uganda. Presented in European Population Conference 2010, Vienna, Austria 1-4 September. 


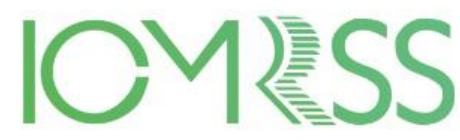

06-08 November, 2020 MUNICH, GERMANY

Aggarwal, R., Netanyahu, S., \& Romano, C. (2001). Access to natural resources and the fertility decision of women: The case of South Africa. Environment and Development Economics, 6, 209-236.

Ajzen, I., \& Klobas, J. (2013). Fertility intentions: An approach based on the theory of planned behavior. Demographic Research, 29(8), 203-232.

Amoateng, A.Y., Heaton, T.B., \& Kalule-Sabiti, I. (2007). Living arrangements in South Africa. In A.Y. Amoateng, \& T.B. Heaton (Eds.). Families and households in postapartheid South Africa: Sociodemographic perspectives. Cape Town: HSRC Press: $43-59$.

Bai, D., Leu, C. S., Mantell, J. E., Exner, T. M., Cooper, D., Hoffman, S., Kelvin, E. A., Myer, L., Constant, D., \& Moodley, J. (2017). An approach to developing a prediction model of fertility intent among HIV-positive women and men in Cape Town, South Africa: A case study. AIDS and behavior, 21(2), 597-609.

Bandehelahi, K., Khoshravesh, S., Barati, M., \& Tapak, L. (2018). Psychological and sociodemographic predictors of fertility intention among childbearing-aged women in Hamadan, West of Iran: An application of the BASNEF Model. Korean Journal of Family Medicine, 1-6.

Batyra, E. (2016). Fertility and the changing pattern of the timing of childbearing in Colombia. Demographic Research, 35(46), 1343-1372.

Bellieni, C. (2016). Pregnancy and undue pressures. Journal of Family and Reproductive Health, 10(3), 104-107.

Benzies, k., Tough, S., Tofflemire, K., Frick, C., Faber, A., \& Newburn-Cook, C. (2006). Factors influencing women's decisions about timing of motherhood. JOGNN, 35(5), $625-633$.

Bimha, P. Z. J., \& Chadwick, R. (2016). Making the childfree choice: Perspectives of women living in South Africa. Journal of Psychology in Africa, 26(5), 449-456.

Casterline, J. B., \& Agyei-Mensah, S. (2017). Fertility desires and the course of fertility decline in sub-Saharan Africa. Population and Development Review, 43(S1), 84-111.

Cheng K. W. (2011). The effect of contraceptive knowledge on fertility: The roles of mass media and social networks. Journal of family and economic issues, 32(2), 257-267. 


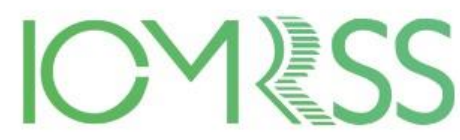

06-08 November, 2020 MUNICH, GERMANY

Ciritel, A., de Rose, A., \& Arezzo, M.F. (2019). Childbearing intentions in a low fertility context: the case of Romania. Genus, 75(4), 1-25.

Creanga, A. A., Gillespie, D., Karklins, S., \& Tsui, A. O. (2011). Low use of contraception among poor women in Africa: An equity issue. Bulletin of the World Health Organization, 89(4), 258-266.

de Jonge, H. C. C., Azad, k., Seward, N., Kuddus, A., Shaha, S., Beard, J., Costello, A., Houweling, T. A. J., \& Fottrell, E. (2014). Determinants and consequences of short birth interval in rural Bangladesh: a cross-sectional study. BMC Pregnancy and Childbirth, 14, 427.

Ferre, C. (2009). Age at first Child: Does education delay fertility timing? The case of Kenya. Policy Research Working Paper No. 4833.

Haile, K., Gebremedhin, M., Berhane, H., Gebremedhin, T., Abraha, A., Berhe, N., Haile, T., Gigar, G., \& Girma, Y. (2016). Desire for birth spacing or limiting and non-use of long acting and permanent contraceptive methods among married women of reproductive age in Aksum Town, North Ethiopia. Contraception and Reproductive Medicine, 1, 22.

Hailu, D., \& Gulte, T. (2016). Determinants of short interbirth interval among reproductive age mothers in Arba Minch District, Ethiopia. International Journal of Reproductive Medicine, 1-17.

Heywood, W., Pitts, M. K., Patrick, K., \& Mitchell, A. (2016). Fertility knowledge and intentions to have children in a national study of Australian secondary school students. Australian and New Zealand Journal of Public Health, 40, 5, 462-467.

Jones, L. E., \& Tertilt, M. (2006). An Economic History of Fertility in the U.S.: 1826-1960. NBER Working Paper No. 12796. Cambridge, MA: National Bureau of Economic Research, Inc.

Khan, J. R., Bari, W., \& Mahbub Latif, A. H. M. (2016). Trend of determinants of birth interval dynamics in Bangladesh. BMC Public Health, 16, 934.

Kuhnt, A., \& Trappe, H. (2013). Easier said than done: Childbearing intentions and their realization in a short-term perspective. MPIDR Working Paper WP 2013-018. 


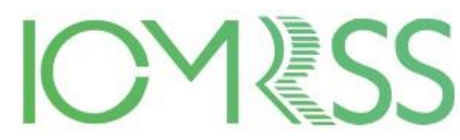

06-08 November, 2020 MUNICH, GERMANY

Lailulo, Y. A., \& Susuman, A. S. (2018). Proximate determinants of fertility in Ethiopia: Comparative analysis of the 2005 and 2011 DHS. Journal of Asian and African Studies, 53(5), 733-748.

Lien, H. M., \& Wang, P. (2016). The timing of childbearing: The role of human capital and personal preferences. Journal of Macroeconomics, 49, 247-264.

Manfredini, M., \& Breschi, M. (2008). Socioeconomic structure and differential fertility by wealth in a mid-nineteenth century Tuscan community. Annales de Démographie Historique, 1(115), 15-33.

Marlow, H. M., Maman, S., Groves, A. K., \& Moodley, D. (2012). Fertility intent and contraceptive decision-making among HIV positive and negative antenatal clinic attendees in Durban, South Africa. Health care for women international, 33(4), 342358.

Matovu, J. K. B., Makumbi, F., Wanyenze, R. K., \& Serwadda, D. (2017). Determinants of fertility desire among married or cohabiting individuals in Rakai, Uganda: A crosssectional study. Reproductive Health, 14(2), 1-11.

McGuire, C., \& Stephenson, R. (2015). Community factors influencing birth spacing among married women in Uganda and Zimbabwe. African Journal of Reproductive Health, 19(1), 14-24.

Miller, W. B. (2011). Differences between fertility desires and intentions: Implications for theory, research and policy. Vienna Yearbook of Population Research, 9, 75-98.

Moultrie, T. A., \& Timæus, I. M. (2001). Fertility and Living Arrangements in South Africa. Journal of Southern African Studies, 27(2), 207-223.

National Department of Health (NDoH), Statistics South Africa (Stats SA), South African Medical Research Council (SAMRC), \& ICF. (2019). South Africa Demographic and Health Survey 2016. Pretoria, South Africa, and Rockville, Maryland, USA: NDoH, Stats SA, SAMRC, and ICF.

Oyediran, K. A. (2005). Fertility desires of Yoruba couples of South-Western Nigeria. Journal of Biosocial Science, 00, 1-20.

Palamuleni, M., Kalule-Sabiti, I., \& Makiwane, M. (2007). Fertility and childbearing in South Africa. In A. Y. Amoateng, \& T. B. Heaton (Eds.). Families and households in 


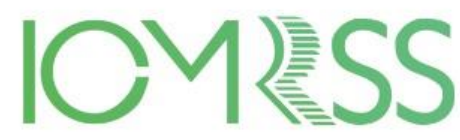

06-08 November, 2020 MUNICH, GERMANY

post-apartheid South Africa: Sociodemographic perspectives. Cape Town: HSRC Press: $113-33$.

Peltzer, K., Sifunda, S., Mandell, L. N., Rodriguez, V. J., Lee, T. K., Cook, R., Weiss, S. M., \& Jones, D. L. (2018). Fertility intentions of prenatal and postpartum HIV-positive women in primary care in Mpumalanga province, South Africa: A longitudinal study. HIV/AIDS (Auckland, N.Z.), 10, 9-17.

Philipov, D. (2011). Theories on fertility intentions: A demographer's perspective. Vienna Yearbook of Population Research, 9(1), 37-45.

Rabbi, A. M. F. (2014). Factors influencing fertility preference of a developing country during demographic transition: Evidence from Bangladesh. South East Asia Journal of Public Health, 4(2), 23-30.

Roser, M. (2020). Fertility rate. https://ourworldindata.org/fertility-rate. Accessed 2 May 2019.

Spéder, Z., \& Kapitány, B. (2009). How are time-dependent childbearing intentions realized? Realization, postponement, abandonment, bringing forward. European Journal of Population, 25(4), 503-523.

Sobotka, T. (2004). Is lowest-low fertility in Europe explained by the postponement of childbearing? Population and Development Review, 30(2), 195-220.

The ESHRE Capri Workshop Group. (2001). Social determinants of human reproduction. Human Reproduction, 16(7), 1518-1526.

United Nations, Department of Economic and Social Affairs, Population Division (UN DESA/Population Division). (2017a). World Population Prospects: The 2017 Revision, Key Findings and Advance Tables. Working Paper No. ESA/P/WP/248.

UN DESA/Population Division. (2017b). World fertility report 2015 (ST/ESA/SER.A/415). New York: UN DESA.

Wei, J., Xue, J., \& Wang, D. (2018). Socioeconomic determinants of rural women's desired fertility: A survey in rural Shaanxi, China. PLoS ONE, 13, 9, e0202968.

Yohannes, S., Wondafrash, M., Abera, M., \& Girma, E. (2011). Duration and determinants of birth interval among women of child bearing age in Southern Ethiopia. BMC Pregnancy and Childbirth, 11, 38. 